ИЗВЕСТИЯ АКАДЕМИИ НАУК ЭСТОНСКОП ССР. ФИЗИКА * МАТЕМАТИКА PROCEEDINGS OF THE ACADEMY OF SCIENCES OF THE ESTONIAN SSR. PHYSICS * MATHEMATICS

$1985,34,3$

Э. РАЯВЕЕ, М. ИОЕЛОВИЧ, Р. ТЭЭЯЭР,

удК $\quad 547.458 .81: 539.122$ О. ПЛОТННКОВ, Э. ЛИППМАА

\title{
ВЛИЯНИЕ ГАММА-ОБЛУЧЕНИЯ НА СТРУКТУРУ ЦЕЛЛЮЛОЗЫ
}

В последнее время большое внимание уделяется модификациям свойств целлюлозы и целлюлозосодержащих материалов путем их $\gamma$-облучения. Показано, что под действием ионизирующих излучений улучшается растворимость $\left[{ }^{1}\right]$ и гидролизуемость $\left[{ }^{2}\right]$ целлюлозы, но ухудшаются прочностные характеристики целлюлозных материалов [3]. В меньшей степени исследовано влияние $\gamma$-облучения на структуру целлюлозы. Установлено, что в результате $\gamma$-облучения происходит снижение степени полимеризации (СП) целлюлозы $\left[^{4,5}\right]$, однако изменений надмолеку-

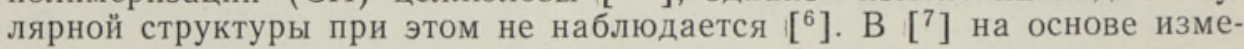
рения теплот смачивания водой отмечалась возможность разрыхления надмолекулярной структуры целлюлозы при $\gamma$-облучении, но сущность этого разрыхления не пояснялась.

Для детального выяснения влияния $\gamma$-облучения на структурные характеристики целлюлозы требуются дальнейшие исследования.

В наших исследованиях использовались образцы хлопковой $(\mathrm{C} \Pi=$ $1200,99 \%$-целлюлозы) и облагороженной древесной $($ СП $=1200$, $98,5 \%$-целлюлозы) целлюлозы. Их $\gamma$-облучение осуществлялось при $20{ }^{\circ} \mathrm{C}$ на установке PX-Y-30 при мощности поглощенной дозы 2,5 Гр/с. Использовались методы рентгеноструктурного анализа, ЯМР ${ }^{13} \mathrm{C}$ высокого разрешения в твердой фазе, ЭПР и вискозиметрии. Рентгенограммы снимались на установке ДРОН-2 (K $\alpha-$ излучение меди). Относительную степень кристалличности $(X)$ целлюлозы находили по методике $\left[{ }^{8}\right]$. Спектры ЯМР ${ }^{13} \mathrm{C}$ высокого разрешения в твердой фазе получили на спектрометре «Bruker CXP-200» с вращением образца под «магическим» углом $\left(54^{\circ} 44^{\prime}\right)$ к направлению магнитного поля. Химические сдвиги ${ }^{13} \mathrm{C}$ измеряли относительно внешнего жидкого тетраметилсилана. Спектры ЭПР макрорадикалов $\gamma$-облученной целлюлозы регистрировали на радиоспектрометре трехсантиметрового диапазона при $-180^{\circ} \mathrm{C}$. Для расчета количества радикалов проводилось двойное интегрирование спектров. Среднюю СП целлюлозы находили по вязкости ее разбавленных растворов в кадоксене $\left[{ }^{9}\right]$.

Исследования показали (таблица), что наиболее характерные структурные изменения целлюлозы при $\gamma$-облучении - это расщепление химических связей и образование макрорадикалов. Разрушение глюкозидных связей приводит к практически идентичному снижению СП как у образцов древесной, так и хлопковой целлюлозы, имеющих одинаковую исходную СП. При дозах облучения 2,5 МГр образуются олигомерные продукты деструкции, СП которых не превышает 10.

При дозах облучения 1,0-1,2 МГр происходит накопление макрорадикалов в сухой целлюлозе, а при более высоких дозах их концентрация остается практически постоянной (таблица). При избытке воды $(0,5$ кг/кг целлюлозы) часть макрорадикалов, находящихся в аморфных областях целлюлозы, рекомбинирует, но сохраняются макрорадикалы, 
Йзменение степени полимеризации (СП) и количества макрорадикалов $(N)$ при $\gamma$-облучении образцов целлюлозы *

\begin{tabular}{l|c|c|c}
\hline \multirow{2}{*}{ Доза, МГр } & СП & \multicolumn{2}{|c}{$N \cdot 10^{-22}$, спин/кг целлюлозы } \\
\cline { 3 - 4 } 0 & $\frac{1200}{1200}$ & Сухой образец & Мокрый образец ** \\
\hline 0,01 & $\frac{680}{700}$ & $\frac{0,26}{0,25}$ & $\frac{0,13}{0,14}$ \\
0,2 & $\frac{110}{110}$ & $\frac{1,03}{1,05}$ & $\frac{0,38}{0,40}$ \\
0,5 & $\frac{57}{60}$ & $\frac{1,20}{1,20}$ & $\frac{0,62}{0,60}$ \\
1,0 & $\frac{45}{48}$ & $\frac{1,30}{1,31}$ & $\frac{0,90}{0,91}$ \\
2,5 & $\frac{1,32}{10}$ & $\frac{1,34}{0,85}$
\end{tabular}

* В числителе приведены данные для древесной, а в знаменателе - для хлопковой целлюлозы.

** Содержание влаги $50 \%$.

расположенные, вероятно, в недоступных для воды кристаллических областях целлюлозы $\left[{ }^{10}\right]$. Эти данные свидетельствуют о том, что разрушение химических связей и образование макрорадикалов при $\gamma$-облучении происходит как в аморфных, так и в кристаллических областях целлюлозы.

Несмотря на значительную деструкцию образцов целлюлозы при $\gamma$-облучении, их кристалличность до дозы 1 МГр практически не изменяется (рис. 1, 2). При дальнейшем увеличении дозы облучения до 2,5 МГр происходит небольшое уменьшение степени кристалличности (на $4-5 \%$ ), причем сохраняется кристаллическая структура, характерная для целлюлозы I. Высокая устойчивость кристаллической структуры целлюлозы к воздействию $\gamma$-облучения связана с наличием общей системы сильных водородных связей [ $\left.{ }^{11}\right]$.

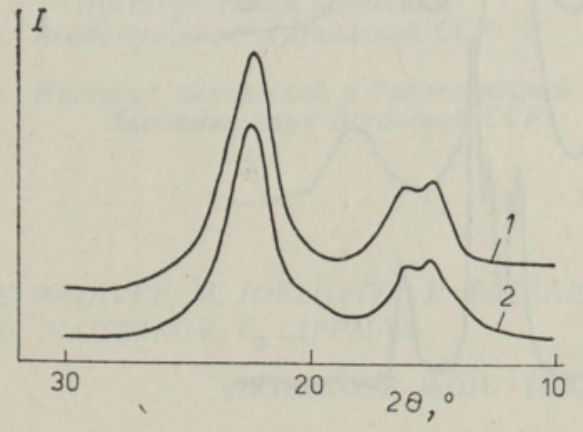

Рис. 1. Рентгенограммы древесной целлюлозы после $\psi$-облучения дозой $0-1 \mathrm{M \Gamma р}(1)$ и $2,5 \mathrm{M \Gamma}$ (2).

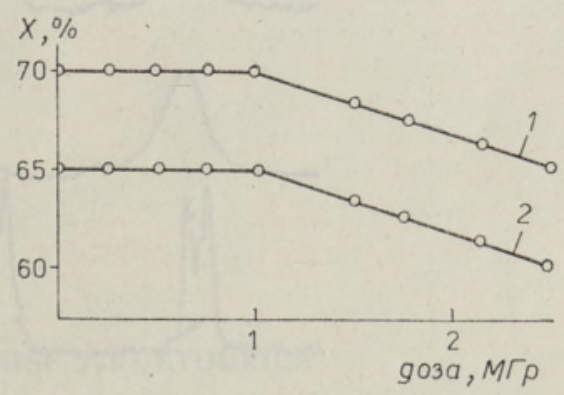

Рис. 2. Зависимость относительной степени кристалличности $(X)$ хлопковой (1) и древесной (2) целлюлозы от дозы $\gamma$-облучения. 
Данные ЯМР ${ }^{13} \mathrm{C}$ отчетливо свйдетельствуют об изменении физической структуры образца. Для спектров высокоупорядоченной микрокристаллической $(a)$ и аморфной (б) целлюлозы (рис. 3) характерно, что при переходе от кристаллической структуры к аморфной сигналы от С4 на 89 м.д. и С6 на 65 м.д. смещаются до 84 и 62 м.д. соответственно. Спектр исходной древесной целлюлозы $(в)$ на рис. 3 содержит как кристаллическую, так и аморфную часть. При дозах облучения до 1 МГр узкие линии уширяются, что характеризует накопление дефектов (нерегулярностей) кристаллической решетки. Незначительное изменение отношения интенсивностей линий на 89 и 84 , а также на 65 и 62 м.д. (рис. 3,2 ) свидетельствует о незначительном изменении степени кристалличности образца до дозы облучения 1,8 МГр. Дальнейшее увеличение дозы $\gamma$-облучения до 2,5 МГр вызывает уменьшение степени кристалличности целлюлозы, что характеризуется уменьшением вклада «кристаллических» и увеличением «аморфных» линий в общий интегральный спектр (рис. $3, \partial$ ). Это обусловлено накоплением дефектов (нерегулярностей) кристаллической решетки - разрывов гликозидных связей - вдоль цепи макромолекулы, а также разрывов и перераспределений водород-

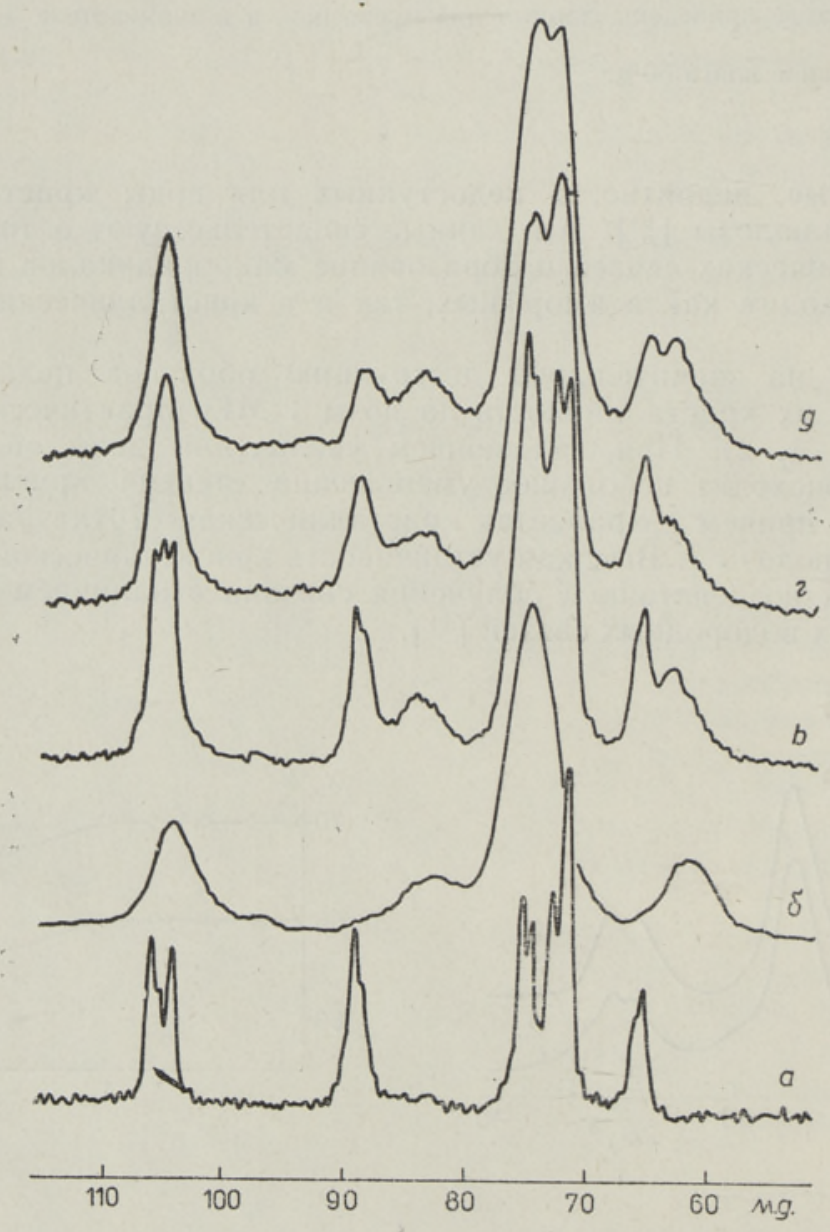

Рис. 3. Спектры ЯМР ${ }^{13} \mathrm{C}$ кристаллической $(a)$, аморфной (б), исходной древесной $(\varepsilon)$ и $\gamma$-облученных целлюлоз дозой $1,8 \mathrm{M \Gamma p}$ (2) и $2,5 \mathrm{M \Gamma p}(\partial)$. 
ных связей с последующим переходом к аморфной структуре. Наблюдается общая тенденция изменения спектра ЯМР от типа а к типу б (рис. 3).

Различий в химических сдвигах или в характере спектров, которые свидетельствовали бы о разрушении глюкопиранозных циклов или об образовании продуктов деструкции, отличающихся от целлюлозы по химической структуре, при дозах $\gamma$-облучения 2,5 МГр и ниже не обнаружено. Концентрация макрорадикалов слишком мала, чтобы каким-то образом оказать влияние на спектр ЯМР.

Таким образом, комплексом физических и физико-химических методов установлено, что при $\gamma$-облучении целлюлозы происходит разрыв хнмических связей основных цепей и боковых групп как в аморфных, так и в кристаллических областях. Однако, благодаря общей системе сильных водородных связей в кристаллических областях, разрушения кристаллической решетки целлюлозы и ее аморфизация при $\gamma$-облучении дозами до 2,5 МГр происходит в незначительной степени. Глюкопиранозные циклы целлюлозы устойчивы к действию ионизирующего облучения.

\section{Л И Т Е РА Т У Р А}

1. Duchaček, V., Bludovsky, R. Radiochem. and Radional. Lett., 38, 31-38 (1979).

2. Каткәвич Р. Г., Каткевич Ю. Ю., Раявее Э. Л. Химия древеснны, № 1, 90-94 (1984).

3. Роговин 3. А. Основы химии и технологии химических волокон. Т. І. М.-Л., «Химия», 1964.

4. Усманов X. У., Разиков $K$. X. Световая и электронная микроскопия структурных превращений хлопка. Ташкент, ФАН, 1974.

5. Ричко Н. Т., Мелешевич А. П., Гордиенко Л. Л., Лепаловская Н. М. Химия древеснны, № 1, 28-32 (1980).

6. Артур Дж. В кн.: Целлюлоза и ее производные. Т. 2. М., «Мир», 1974, 256-287

7. Усманов Х. У., Калабановская Е. Н., Дамовский Р. Б. Высокомол. соед., 3, № 2, 223-227 (1961).

8. Ноелович М. Я., Веверис Г. П. Химия древесины, № 2, 10-14 (1983).

9. Оболенская А. В. Практические работы по химии древесины и целлюлозы. М., «Лесн. пром.», 1965, 411.

10. Папков С. П., Файнберг Э. З. Взаимодействие целлюлозы и целлюлозных материалов с водой. М., «Химия», 1976.

11. Жбанков Р. Г., Козлов П. В. Фнзика целлюлозы и ее произаодных. Минск, «Наука и техника», 1983.

Ннститут химии
Академии наук Эстонской ССР

Ннститут химии древесины

Академии наук Латвийской ССР

Институт химической и биологической физики Академии наук Эстонской ССР
Поступила в редакцию 6/VII 1984

\section{E. RAJAVEE, M. JOELOVITS, R. TEEÄAR, \\ O. PLOTNIKOV, E. LIPPMAA}

\section{$\gamma$-KIIRGUSE MOJU TSELLULOOSI STRUKTUURILE}

On uuritud tselluloosi struktuuri muutusi $\gamma$-kiirguse toimel EPR-, TRM- ja röntgenspektroskoopia abil. Kiiritamisel katkevad molekulidevahelised ja makromolekulidesisesed keemilised sidemed nii amorfsetes kui ka kristalsetes piirkondades. Glükopüranoosi ringide katkemist ei täheldatud. Kasutatud dooside piirkonnas (kuni 2,5 MGy) langes vähesel määral tselluloosi kristalsuse aste. Esmakordselt on kiiritatud tselluloosi uurimisel rakendatud kõrge lahutusega tahke keha TMR-spektroskoopiat. 
E. RAJAVEE, M. JOELOVICH, R. TEË̈ÄR,

O. PLOTNIKOV, E. LIPPMAA

\section{INFLUENCE OF THE $\gamma$-IRRADIATION ON THE STRUCTURE OF CELLULOSE}

Structural changes in the $\gamma$-irradiated samples of wood and cotton cellulose were studied by ESR, viscosimetry, X-ray spectroscopy and NMR techniques. Solid state dipolar decoupling and magic angle sample spinning were used in the NMR studies. Irradiation causes breaking of the inter- and intramolecular hydrogen and chemical bonds and creation of macroradicals in amorphous as well as in the crystalline regions of the sample. This is shown by the number of radicals determined by ESR spectroscopy and broadening of the sharp crystalline lines in the NMR spectrum. Ratio of the integral intensities of the «crystalline» and «amorphous» lines at 89 and $84 \mathrm{ppm}$ in the carbon-13 NMR spectrum remains nearly the same up to $1.8 \mathrm{MGy}$ doses, which indicates little change in crystallinity. A 2.5 MGy irradiation dose decreases the crystallinity, but the glucopyranose rings remain stable and sample presents a mixture of amorphous and crystalline native cellulose. There is no evidence of the formation of substances diferent from cellulose through $\gamma$-irradiation at the doses used.

Solid state high resolution NMR proved to be a useful tool for the study of $\gamma$-irradiated cellulose samples. 